\title{
THICKNESS AND BASAL CONFIGURATION OF LOWER BLUE GLACIER, WASHINGTON, DETERMINED BY GRAVIMETRY
}

\author{
By Charles E. Corbató \\ (Department of Geology, University of California, Los Angeles, U.S.A.)
}

\begin{abstract}
Gravity measurements at 146 stations on lower Blue Glacier were used to determine the subglacial bedrock configuration. The gravity values, station elevations and density contrast were carefully measured, and terrain corrections thoroughly evaluated to insure accuracy of the Bouguer anomalies. A series of successive approximations results in evaluation of the regional gravity field and a three-dimensional model of the glacier whose gravimetric effects fit the range of the observational and computational errors. Comparison with bore holes and seismic reflections indicates no significant errors in the model and accuracies of $5^{-10}$ per cent in the calculated thicknesses of the glacier.
\end{abstract}

RÉsumÉ. Détermination par gravimétrie de l'épaisseur et de la configuration du socle rocheux du bas Blue Glacier, Washington. De I 46 observations de gravité, relevées sur la partie inférieure du Blue Glacier, on a déduit la topographie du fond du glacier. La gravité, l'élévation et les densités ont été soigneusement mesurés, et les corrections de terrain ont été calculées avec rigeur afin de s'assurer des anomalies de Bouguer précises. Par approximations répétées, on évalue le champ régional de gravité et le modèle spatial d'un glacier qui dans son ensemble donnent un champ presque identique avec celui observé. On n'admet que des erreurs du même ordre que les erreurs d'observation et de calcul. En comparant ces résultats avec des épaisseurs obtenues par forage jusqu'au fond du glacier et par la méthode sismique par réflexion, on peut constater que les erreurs sont négligeables et que la précision est de $5^{-10} \%$.

\begin{abstract}
Zusammenfassung. Bestimmung von Dicke und Untergrundsform des unteren Blue Glacier, Washington, aus Schweremessungen. Schweremessungen auf ${ }_{14} 6$ Stationen im unteren Teil des Blue Glacier wurden zur Bestimmung der Topographie der Gletscherunterfläche benutzt. Um verlässliche Bouguer-Anomalien zu erhalten, wurden unter Berücksichtigung topographischer Korrektionen die Schwerewerte, die Höhen der Messpunkte und die Dichteunterschiede sorgfältig bestimmt. Durch eine Reihe schrittweiser Annäherungen wurde ein regionales Schwerefeld und ein räumliches Modell des Gletschers errechnet, deren Schwereverteilung innerhalb der Mess- und Rechengenauigkeit mit den Beobachtungen übereinstimmt. Ein Vergleich mit Ergebnissen von Bohrungen und seismischen Reflexionsmessungen zeigt, dass die Fehler des Modells unerheblich sind und dass die berechnete Gletscherdicke innerhalb von $5^{-10} \%$ korrekt ist.
\end{abstract}

\section{INTRODUCTION}

Blue Glacier is situated near the center of the Olympic Peninsula of north-western Washington (lat. $47^{\circ} 5 \mathrm{o}^{\prime} \mathrm{N}$., long. $123^{\circ} 45^{\prime} \mathrm{W}$.). The glacier descends on the north side of Mount Olympus $(2,428 \mathrm{~m}$.) over an ice fall into a northerly-trending canyon and terminates at an elevation of $\mathrm{I}, 250 \mathrm{~m}$. The part below the ice fall which is nearly all in the ablation area and is usually termed lower Blue Glacier has a length of about 2,500 m. and a width of from 500 to $\mathrm{I}, 200 \mathrm{~m}$. This region of the glacier has a relatively smooth upper surface sloping from $5^{\circ}$ to $10^{\circ}$ in the direction of flow and has been the site of much previous glaciological research.

Previous investigations on Blue Glacier have principally been to study the budget of the glacier and to study the style and mechanisms of glacier flow. Of importance in evaluation in this research is knowledge of the bedrock configuration beneath the glacier. In 1957 C. R. Allen made a seismic survey of the lower glacier (from a paper on surface-velocity and surface strain-rate data from lower Blue Glacier to be published by M. F. Meier, C. R. Allen, W. B. Kamb and R. P. Sharp). Although good reflections were obtained in some parts of the glacier, none was obtained in highly crevassed areas or above the firn line, and complex reflections in many areas indicate that the glacier bed has considerable local relief. Therefore, a gravity survey was conducted during the summers of 1960 and I96I to provide data to determine more completely the depth and shape of the glacier. The gravity data proved to be useful for the intended purpose, and the gravimetric investigations have led to certain conclusions interesting in their own right because of the simplicity of a valley glacier with its singular shape, known density contrast and known upper surface. 
Gravity Survey

Gravity measurements

All gravity measurements were made with Worden gravimeter 236 (surveying model) belonging to the Division of Geological Sciences, California Institute of Technology. The dial constant of the meter given by the manufacturer is $0.190 \mathrm{I}(5) \mathrm{mgal}$./small dial scale division, a value which agrees well when compared with a calibration range of several hundred milligals. Long-period meter drift averaged about I mgal./day. Earth tides and temperature changes caused greater short-period drift rates; however, drift of the instrument in the field did not exceed $0.2 \mathrm{mgal}$./hr. Drift corrections were distributed linearly with respect to time of observation.

Gravity was measured along ro traverses transverse to the glacier (Fig. I). The west end of each traverse was re-occupied to correct for meter drift and these stations were all tied together through a common base station. The meter does not have a range adequate to allow simple tying of the network to a known gravity value, so that only relative differences were obtained. These relative differences probably have errors of about $\mathrm{o} \cdot \mathrm{I}$ mgal.

\section{Gravity stations}

The seven northernmost traverses and the next to southernmost traverse were measured during August I 960 . On the basis of the promise of these results two additional traverses were made in August 196r. A total of 146 stations was occupied, 20 of which are on bedrock. Elevations and positions of the stations at the ends of the traverses and of all the stations measured in the second year were determined by theodolite measurements from the triangulation network previously established by Meier around Blue Glacier (from a paper on surfacevelocity and surface strain-rate data from lower Blue Glacier to be published by M. F. Meier, C. R. Allen, W. B. Kamb and R. P. Sharp). Small vertical refraction and curvature corrections to the vertical angle measurements were made using an empirical formula which gives good agreement on lower Blue Glacier for shots to the same point from different triangulation points. Station elevations the first year were determined by levelling on the glacier. Closure of the level lines was less than $0.2 \mathrm{~m}$. and this error was distributed evenly among the stations of the traverse. The elevations of the stations are probably known to the closest $0.2 \mathrm{~m}$., which can produce in the Bouguer anomalies a possible error of 0.04 mgal. In addition it should be mentioned that station elevations were determined within $8 \mathrm{hr}$. of the gravity observations, so that ablation and down-slope movement of the glacier contribute little to elevation errors.

\section{Reduction of Gravity Data \\ Bedrock and ice densities}

The density of the glacier ice was not measured but is assumed to be $0.90 \mathrm{~g} . / \mathrm{cm} .^{3}$ (Seligman, 1950). Low-grade metamorphic rocks of either Mesozoic or early Tertiary age form the bedrock surrounding Blue Glacier. The mean density of 33 relatively unweathered samples of bedrock collected at random from morainal deposits was determined by means of a Jolly balance to be $2.73 \mathrm{~g} . / \mathrm{cm} .^{3}$ with a range from 2.68 to $2.77 \mathrm{~g} . / \mathrm{cm} .^{3}$. The variation in the measurements is shown in Table I.

Table I. Bedrock Densities

\section{Rock type}

Metamorphosed mudstones and shales

Metamorphosed sandstones

Metamorphosed pebbly sandstones and conglomerates

Total

$\begin{array}{ccc}\begin{array}{c}\text { Number of } \\ \text { samples }\end{array} & \begin{array}{c}\text { Mean density } \\ \text { standard deviation })\end{array} & \text { Range } \\ & \mathrm{g} / \mathrm{cm} .^{3} & \\ 9 & 2 \cdot 74 \pm 0 \cdot 02 & 2 \cdot 70-2 \cdot 77 \\ 18 & 2 \cdot 72 \pm 0 \cdot 02 & 2 \cdot 69-2 \cdot 77 \\ 6 & 2 \cdot 73 \pm 0 \cdot 03 & 2 \cdot 68-2 \cdot 76 \\ 33 & 2 \cdot 73 \pm 0 \cdot 02 & 2 \cdot 68-2 \cdot 77\end{array}$




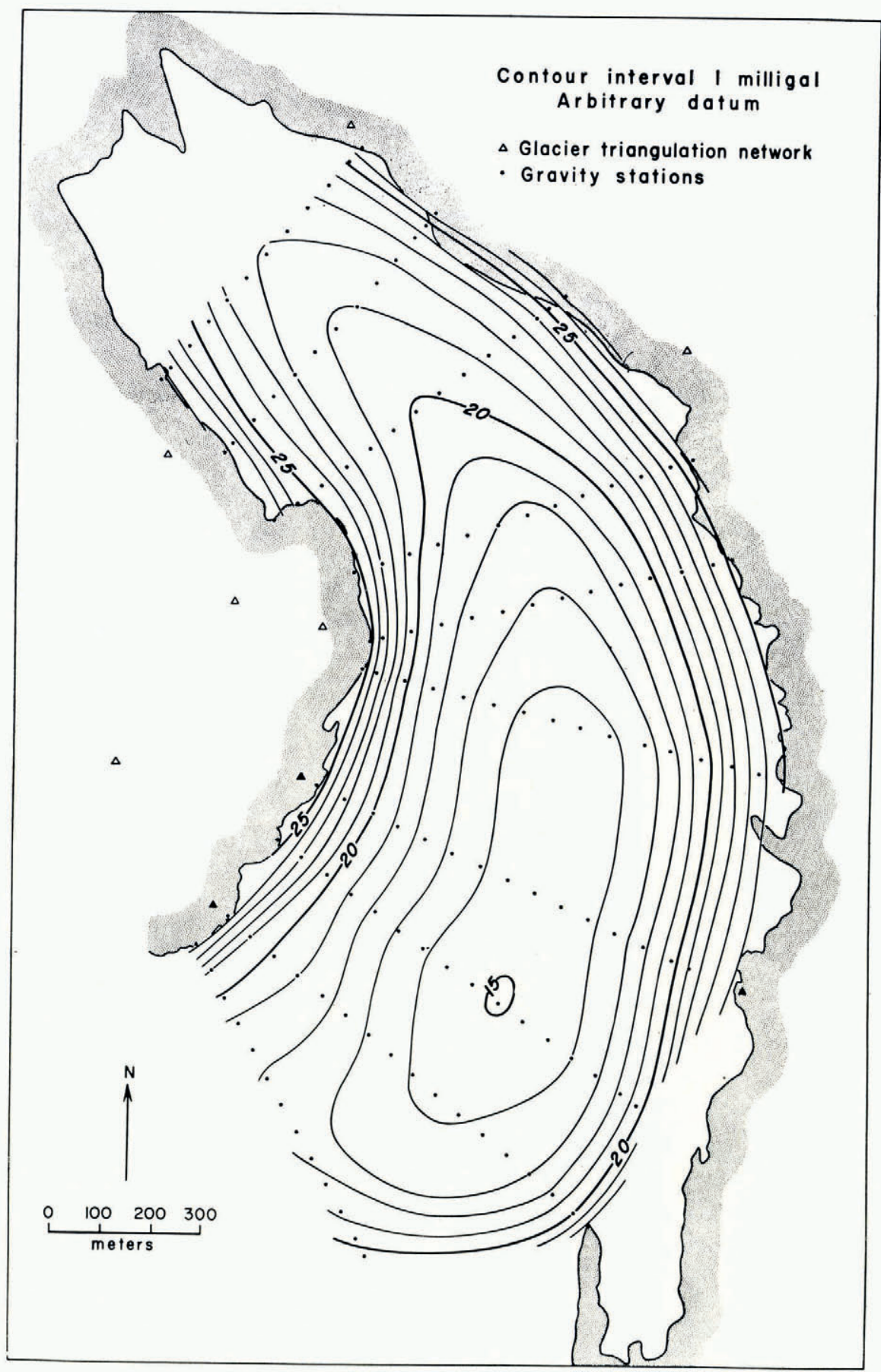

Fig. I. Bouguer anomaly map of lower Blue Glacier 


\section{Terrain corrections}

The gravitational effect of the topography around each station was calculated by means of graticules using the scheme of Hammer (1939) out to a distance of $6 \cdot 7 \mathrm{~km}$. from each station (through zone "J"). In areas of high relief an extension of the original tables (Corbató, I 963 , p. r8-19) was utilized. Because of the availability of topographic maps of good quality (U.S. Geological Survey, Mount Olympus quadrangle, 1956, I:62,500; American Geographical Society, I 960 , Blue Glacier map, $\mathrm{I}: \mathrm{r} 0,000)$, it is felt that accurate terrain corrections can be applied to the data even though the magnitude of the corrections is high (from 6 to I 3 mgal.). (The elevations of the glacier shown in the illustrations are based on the triangulation network of M. F. Meier, C. R. Allen, W. B. Kamb and R. P. Sharp for lower Blue Glacier. Comparison with the map of the American Geographical Society ( 1960 ) indicates a systematic difference between the two with Meier's network having elevation values $9 \mathrm{~m}$. below those of the published map. This error does not appear to be significant in computing the terrain correction.) The density used in making the corrections for all compartments is $2 \cdot 73 \mathrm{~g} . / \mathrm{cm} .{ }^{3}$. Kanasewich (1963, p. 618) used the density of ice for compartments which are on the glacier but this implies a previous knowledge of the glacier configuration. It seems preferable to place this aspect of the problem into the interpretation of the anomalies. Figure 2 shows the surface elevations during the summers of i96o-6I and the approximate configuration of the terrain correction function. The divergence of this function from a simple form indicates that simplifying assumptions (e.g. Bull and Hardy, i 956) can introduce large errors. Repeated computation of terrain corrections on Blue Glacier indicates that these values have a precision of about $0 . \mathrm{I}$ mgal. and an accuracy of perhaps $\pm 0.2 \mathrm{mgal}$.

\section{Elevation and latitude corrections}

An elevation correction (combined free-air and Bouguer) was computed for each of the stations using a factor of $0 \cdot 1943 \mathrm{mgal} . / \mathrm{m}$., corresponding to a density of $2.73 \mathrm{~g} . / \mathrm{cm} .{ }^{3}$. In addition latitude corrections were calculated using the standard international gravity formula.

\section{Bouguer anomalies}

The Bouguer anomalies (Fig. I) represent the observed gravity values corrected for topography, elevation and latitude. The datum is an arbitrary one as only relative differences in gravity were observed. One would expect these anomalies to reflect basically the mass deficiency of the glacier, and they do with the higher values at the margins and the lower values in the center where the glacier is thicker. Total range of the anomalies is about $13 \mathrm{mgal}$. with a probable error at the stations of at most $\pm 0.3 \mathrm{mgal}$.

\section{INTERPRETATION}

\section{Previous interpretations on valley glaciers}

The interpretation of gravity anomalies presents many problems, principally because there is no direct solution for the disturbing body. Among the cases for which it can be shown that there is, in principle, a unique solution is the one in which the anomalies are caused by a single mass of known density and at least one point on the boundary of the body is known (Skeels, I 947; Roy, I962). Such is the case of a valley glacier. However, the greatest difficulty arises here in ordinarily not being able to measure gravity at any distance from the glacier so that the regional gravity field (i.e. the resulting anomalies formed by raising the glacier density to that of the bedrock) is an unknown quantity. Let us consider what some previous workers have done.

Bull and Hardy (1956), who were the first to measure gravity on a valley glacier (Austerdalsbreen, Norway), assumed that the anomaly values measured at the edges of the 


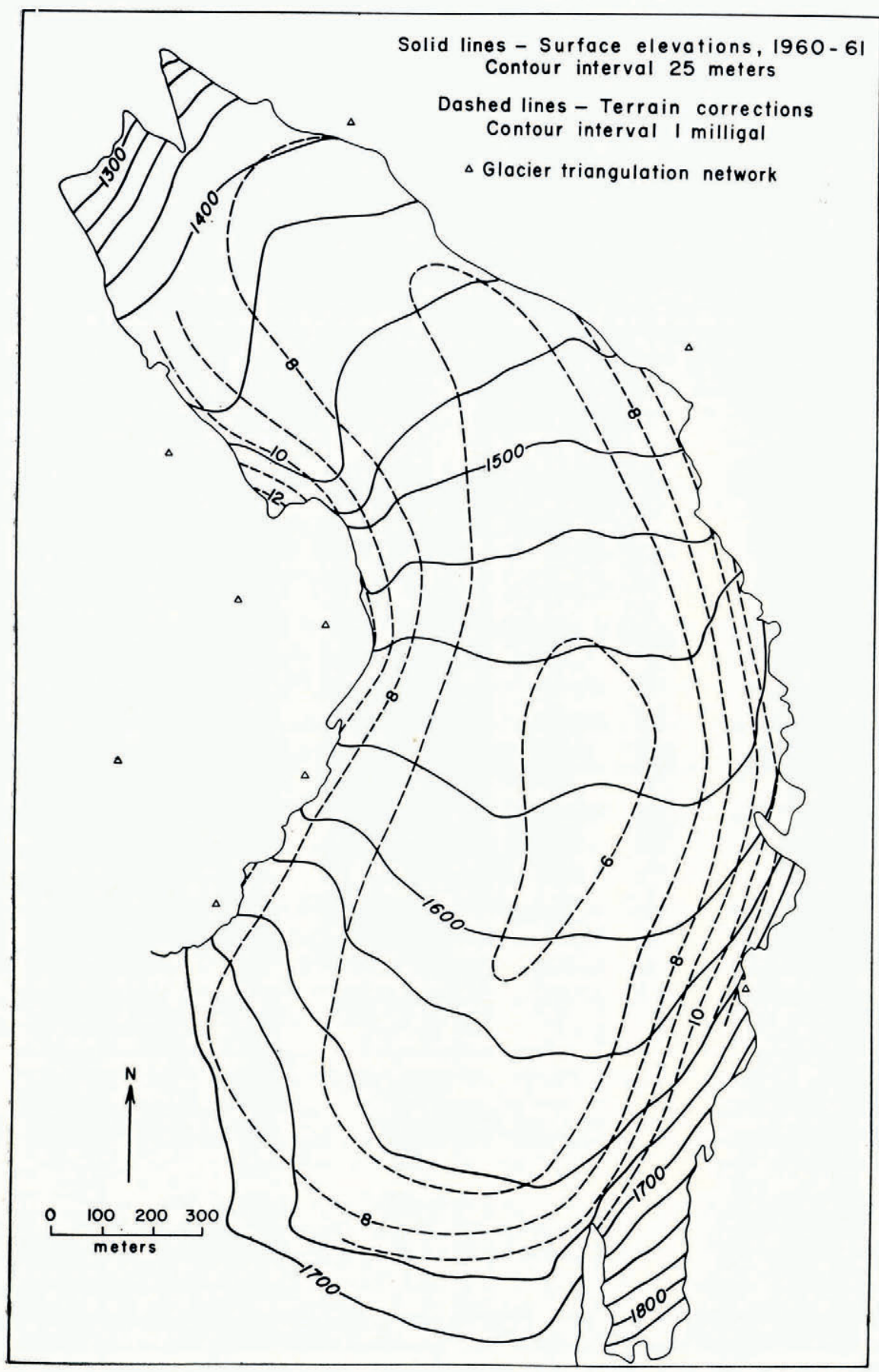

Fig. 2. Surface elevations (I96O-6I) and terrain corrections 
glacier represent the regional gravity. The resulting residuals were then converted linearly into depths using the factor for an infinite slab. Unfortunately both these premises tend to make the glacier depths too shallow; subsequent bore holes have confirmed this.

Thiel and others (1957) used an identical method for a first approximation on Lemon Creek Glacier, Alaska. This model was then adjusted using a two-dimensional graticle process. No mention is made of how closely the model fits their observed values.

Caputo (1958) used a two-dimensional semi-elliptical first approximation to get one gravity profile on Baltoro Glacier. Further adjustments were made by a two-dimensional analytical procedure.

Russell and others ( 1960 ) made the same assumptions as Bull and Hardy about the regional gravity but they did recognize the critical nature of the terrain corrections at the margins of the glacier. Depths were calculated by using a two-dimensional iterative procedure.

Kanasewich (1963) initially used a family of two-dimensional parabolic shapes, choosing the one which best fit his observed anomalies as a first approximation to a three-dimensional model. Anomalies were calculated for this model and the model then adjusted. Unfortunately he gives an inadequate description of the ultimate model, but it appears that the differences between the anomalies calculated for it and his observed values are small.

\section{Model I-two-dimensional parabolas}

For a n̂rst approximation in interpreting the gravity on Blue Glacier, the anomalies caused by two-dimensional parabolic bodies with vertical symmetry axes and horizontal upper surfaces (Corbató, I 964) were compared with the observed Bouguer anomalies. No attempt was made at a mathematical "best-fit"; only the mean relative differences between the center of the glacier and the margins were used to select the parabola. The resulting configuration of the bedrock is shown in Figure 3. While this map is of no real value because of the approximations involved, it is presented here for comparison with the other procedures.

\section{Model II-two-dimensional least-squares procedure}

A procedure has recently been devised (Corbató, 1965) which is useful for adjusting two-dimensional models. Corrections to an initial model are made by a least-squares approximation which uses the partial derivatives of the anomalies so that the residuals between the calculated and observed anomalies are reduced to a minimum. In comparison with other iterative techniques, convergence is very rapid. The most convenient method to use for both the calculation of the anomalies and the adjustments is the two-dimensional scheme of Talwani and others (1959) in which the outline of the body is polygonized and the anomalies and the partial derivatives of the anomaly with respect to the depth of a vertex on the body can be expressed as functions of the coordinates of the vertex. A useful aspect of this procedure is that not only the depths can be evaluated but the regional gravity can also be considered as one of the unknowns.

Ten two-dimensional profiles matching the gravity lines were calculated using this procedure. Regional gravity was considered an unknown of the form $a+b x$ (where $a$ and $b$ are constants and $x$ is the distance across the profile) and was evaluated for each profile. For the first approximations of the depths, the values of model I were used. The number of points on the bottom of the glacier whose elevations were determined was allowed to vary from 3 to about Io. With a larger number of points the computed bottom profile becomes increasingly jagged (i.e. high elevations alternate with small ones), reflecting the "noise" inherent in the Bouguer anomalies. The least-squares procedure smoothes this noise when the number of variables is small with respect to the number of observations. For most profiles the values were best when the number of variables was about one-half the number of observations. These depths were then contoured to form model II (Fig. 4). Principal changes from model I are the 


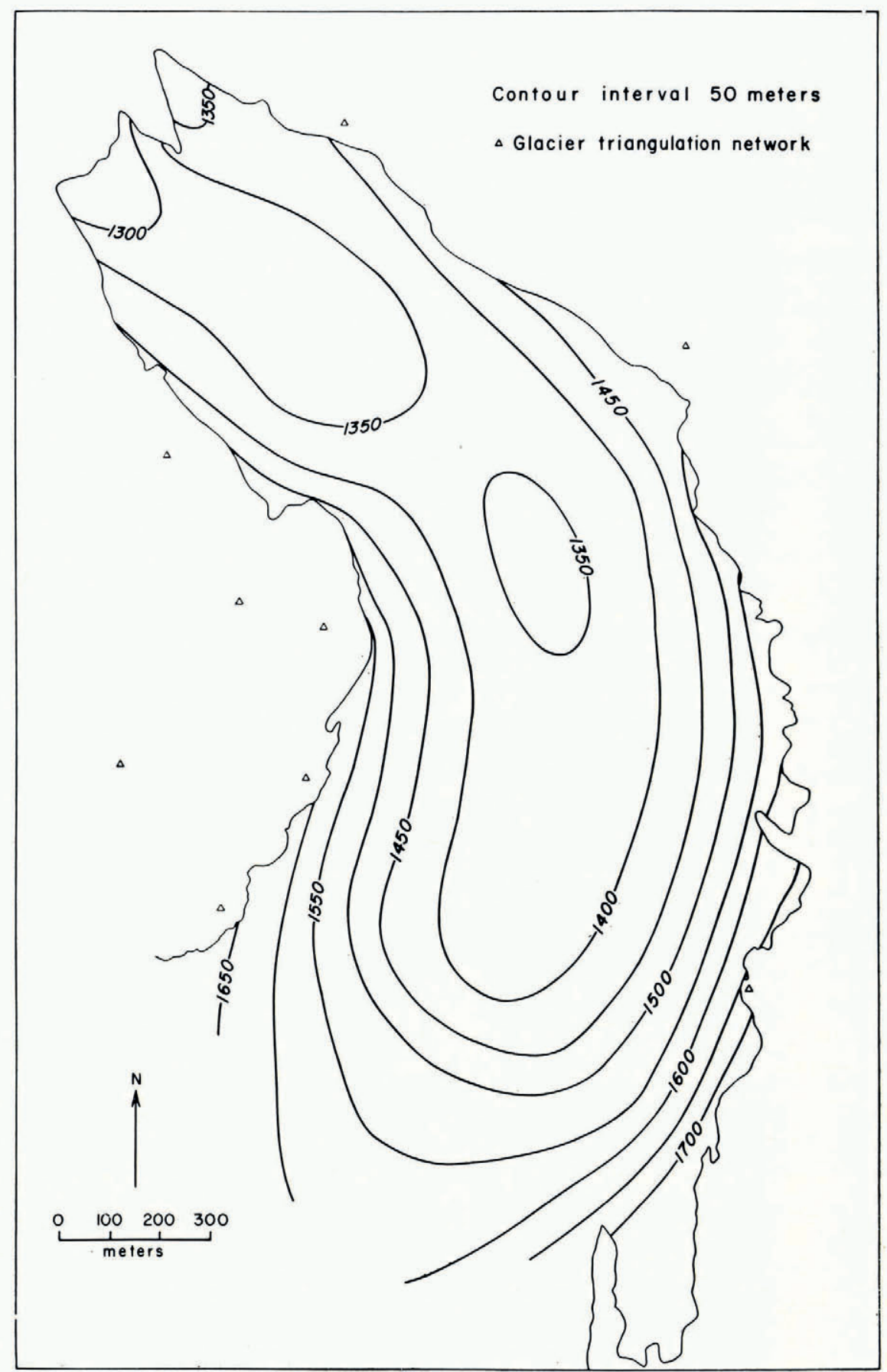

Fig. 3. Model I. Bedrock contours based on two-dimensional parabolas 
deepening of the two basins of the valley and the introduction of a third basin at the southern end of the valley.

\section{Model III-three-dimensional procedure}

It was recognized at the start of the interpretation that lower Blue Glacier could not very well be considered a two-dimensional body. The ice fall at the southern end, the sharp bend in the middle and the proximity of the terminus to several gravity profiles all tend to make this a poor assumption. The ideal situation would be to be able to apply the least-squares procedure to a three-dimensional model, adjusting the model to the best fit and at the same time solving for the regional gravity. However, the problems inherent in solving upwards of $\mathrm{I} 5 \mathrm{o}$ equations in i 50 unknowns and the lack of a fast procedure for both calculating the effects of and adjusting a three-dimensional model prohibit this. Instead it was decided to assume a regional gravity and a model based on the two-dimensional least-squares procedure (model II), calculate the gravity effects by the method of Talwani and Ewing ( 960 ), and make whatever adjustments might be necessary by inspecting the resulting residuals.

A value of the regional gravity was determined by assuming it to be of the form $a+b x+c y$ ("planar"; $a, b$ and $c$ are constants, $x$ and $y$ are map coordinates) and fitting by least-squares the values of the regional gravity calculated for the stations on bedrock in the preceeding two-dimensional analysis. After the first set of residuals was obtained the value of the regional gravity was adjusted slightly, assuming that the model then was basically correct and any changes at the center of the glacier would only modify values at the bedrock stations by a small amount. The resulting regional gravity field has a slope of $+0.77 \mathrm{mgal} . / \mathrm{km}$. in a N. $15^{\circ} \mathrm{W}$. direction, a value that agrees very well in both direction and magnitude with that measured by Stuart (196r, p. 274) in this part of the Olympic Mountains.

Gravity anomalies of the three-dimensional model were calculated by the method of Talwani and Ewing ( 1960 ) in which the effects of horizontal laminae of the body are computed and then numerically integrated from the bottom to the top of the body. The boundary of a lamina is approximated by an irregular $n$-sided polygon and the gravitational attraction per unit height can then be expressed as a function of the coordinates of the vertices of the polygon. A more efficient form for machine calculation of equation (8) of Talwani and Ewing (1960, p. 208) was used in the computation.

For a right-handed coordinate scheme with $z$ positive upwards, vertices numbered in a clockwise direction (looking down)

$$
V=-(\operatorname{sign} z) \gamma \rho \sum_{i=1}^{n} \tan ^{-1}\left(P_{i} / Q_{i}\right) \quad\left(-\pi \leqslant \tan ^{-1} \frac{P_{\mathrm{I}}}{Q_{\mathrm{I}}} \leqslant \pi\right)
$$

where $\gamma$ is the gravitational constant, $\rho$ is the density and

$$
\begin{array}{rlrl}
P_{i} & =T_{i} A_{i}+S_{i} B_{i} & A_{i} & =|z| S_{i}\left(D_{i} C_{i j}+D_{j} C_{i i}\right) \\
Q_{i} & =\mathcal{T}_{i} B_{i}-S_{i} A_{i} & B_{i} & =S_{i}^{2} D_{i} D_{j}-z^{2} C_{i i} C_{i j} \\
R_{i} & =x_{i}{ }^{2}+y_{i}{ }^{2} & C_{i j} & =T_{i}-R_{j} \\
S_{i} & =x_{j} y_{i}-x_{i} y_{j} & D_{i} & =+\left(R_{i}+z^{2}\right)^{\frac{1}{2}} \\
T_{i} & =x_{i} x_{j}+y_{i} y_{j} & j & =i+\mathrm{I} .
\end{array}
$$

Instead of calculating the arctangents and then summing, it is usually more efficient to compute only one arctangent (with a value between zero and $2 \pi$ ) after combining terms by repeated use of the formula

$$
\tan ^{-1}\left(\frac{P_{a}}{Q_{a}}\right)+\tan ^{-1}\left(\frac{P_{b}}{Q_{b}}\right)=\tan ^{-1}\left(\frac{P_{a} Q_{b}+P_{b} Q_{a}}{Q_{a} Q_{b}-P_{a} P_{b}}\right) .
$$

The model chosen for lower Blue Glacier consists of 18 horizontal laminae spaced at $25 \mathrm{~m}$. intervals, each averaging about 28 vertices. The time required to make this computation 


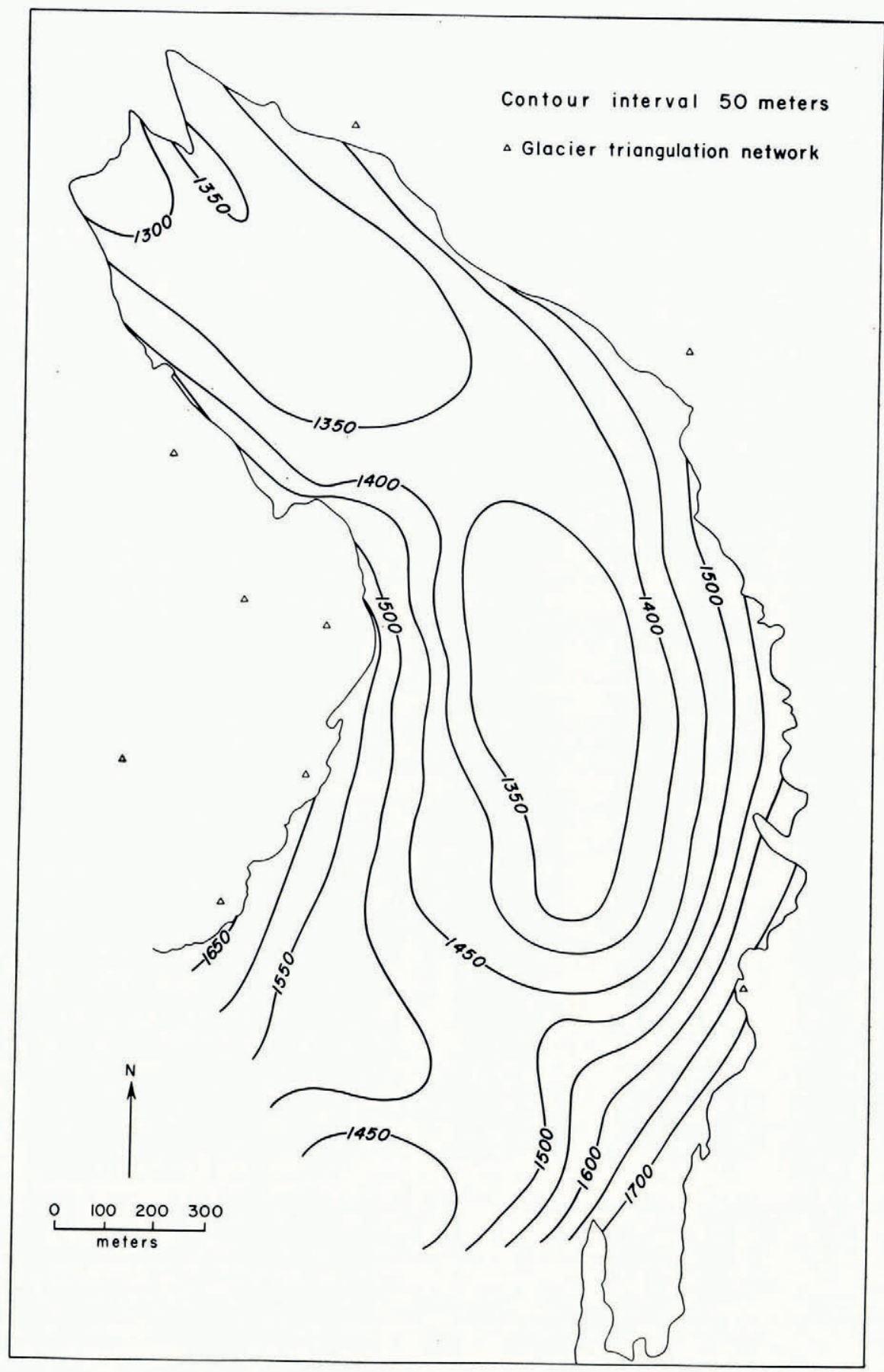

Fig. 4. Model II. Bedrock contours based on two-dimensional least-squares procedure 
on an IBM 7090 digital computer is about $\mathrm{I} \cdot 6 \mathrm{msec}$. $/$ vertex, or for the 146 stations, a total time of 2 min.

Numerical integration of the model (Fig. 5) presents a problem not previously encountered either by Talwani and Ewing (1960) or by Kanasewich (1963), who used this method in interpreting gravity on Athabaska Glacier. As the laminae approach the elevation of an observation point on the surface of the glacier, the value of the anomaly per unit height does not approach zero, but approaches the values of $\pm \alpha \gamma \rho$, where $\alpha$ is the horizontal angle subtended by the glacier at the station, $\gamma$ is the gravitational constant, and $\rho$ is the density. Both these points are shown on Figure 5, where for a station in the middle of the glacier $\alpha$ is about equal to $\pi$. The part of the glacier above the station and the discontinuity in the integrand were eliminated by Kanasewich $(1963$, p. 618,622 ) by incorporating this aspect into the terrain correction. For his method $\alpha$ is then $2 \pi$. On the lower Blue Glacier model a value of $\alpha$ was estimated for each station.

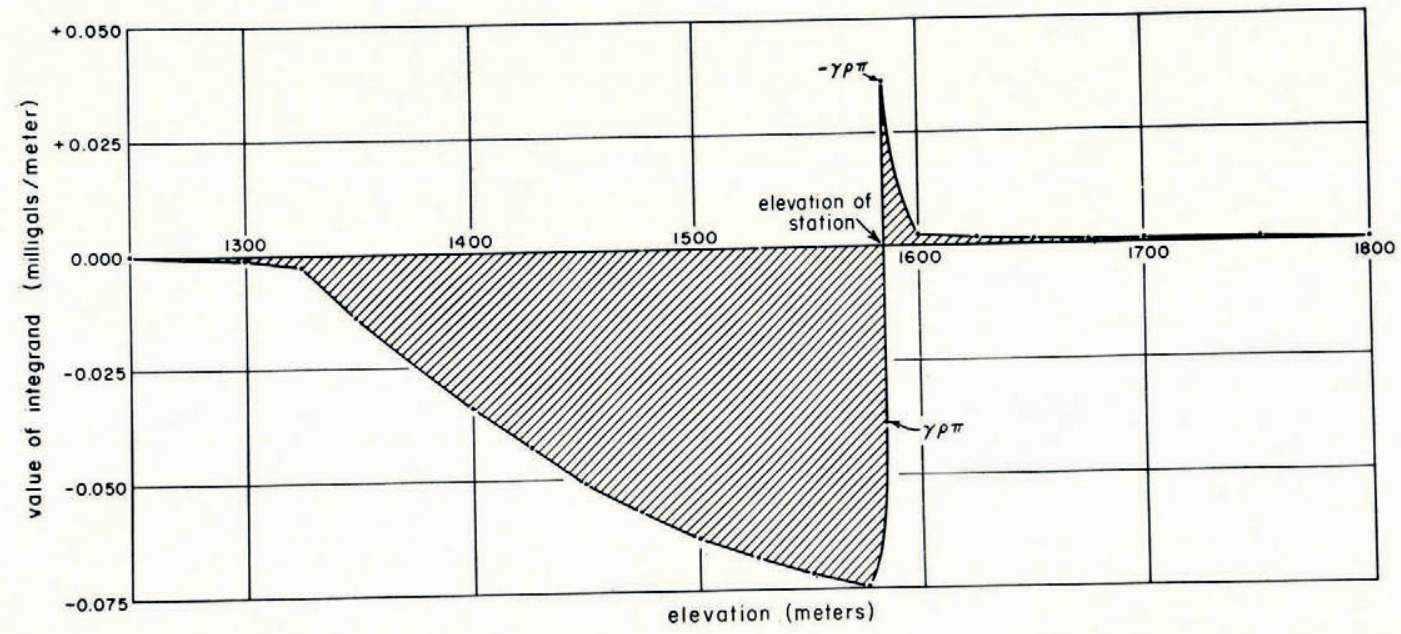

Fig. 5. Example of numerical integration for station in the center of the glacier

The integration was performed by the trapezoidal method, except for the parts immediately above and below the observation point, where the value of the integrand changes most rapidly. Here the integrand is approximated by a part of a parabola so as to fit better the real function (although the ideal solution would be to solve for more values of the integrand). The precision of this method for calculating gravity on the model of Blue Glacier seems at best $0.2 \mathrm{mgal}$. Greater precision would necessitate describing the model in much more detail (i.e. more laminae with more vertices), requiring an effort hardly commensurate with the significance.

The first model used in the three-dimensional calculations was that derived by the twodimensional least-squares procedure (model II). The root-mean-square value of the residuals was as large as $3 \mathrm{mgal}$. The model was then adjusted by inspection of the residuals and the computation repeated. After the third set of adjustments the root-mean-square of the residuals was only $0.4 \mathrm{mgal}$. and further modification of the model seemed unnecessary. Numerical distribution of the residuals is shown in Table II. Areally the large residuals are quite randomly scattered, suggesting that the procedure has reached the "noise level" of the Bouguer anomalies and the computational method. If anything, there is a slight correlation between the size of the residual and the proximity of the margin of the glacier, which seems to suggest errors in the larger terrain corrections. 
Table II. Numerical. Distribution of Residuals for Model III

$\begin{array}{crc}\begin{array}{c}\text { Less than } \\ \text { mgal. }\end{array} & \begin{array}{c}\text { Number of stations } \\ \text { per cent }\end{array} \\ 0 \cdot 2 & 55 & 37 \cdot 7 \\ 0 \cdot 4 & 107 & 73 \cdot 3 \\ 0 \cdot 6 & 127 & 87 \cdot 0 \\ 0 \cdot 8 & \text { 1 } 36 & 93 \cdot 2 \\ 1 \cdot 0 & 142 & 97 \cdot 3 \\ \text { Greater than or equal } & & \\ \text { mgal. } & & \\ \text { i. } & & \\ & 4 & 2 \cdot 7\end{array}$

The final adjusted model (III) is shown in Figure 6 together with the thicknesses obtained by subtracting the bedrock contours from the surface elevations (Fig. 2).

Principal changes in going from model II to model III are the deepening and flattening of the northern basin, the deepening of the central depression (with a maximum thickness of about $28 \mathrm{om}$.) and the elimination of the poorly defined southern basin. Of interest is the remarkable correspondence of bedrock topography above and below the surface of the glacier, particularly the relatively low slopes in the south-western part, the steep slopes on the southeastern side, and the continuation of the western rock buttress at the main turn of the glacier.

\section{Comparison with independently determined bedrock elevations}

A number of bore holes have been drilled on lower Blue Glacier that limit the highest bedrock elevations at their respective sites (Fig. 6). Table III compares the actual elevations at the bottom of the bore holes with the hypothetical elevations of model III. Only one bore hole ("J") is known to have reached bedrock but the gravimetrically determined model suggests that bore holes " $L$ " and " $B$ " also reached the bottom of the glacier. The mean difference between the model and the actual glacier for these three bore holes is $5 \mathrm{~m}$. All other bore holes fit the model.

Table III. Comparison of Gravimetrically Determined Elevations and Maximum Elevations Determined by Bore Holes

\begin{tabular}{|c|c|c|c|}
\hline $\begin{array}{l}\text { Bore } \\
\text { hole }\end{array}$ & Year & $\begin{array}{c}\text { Elevation } \\
\text { penetrated } \\
\mathrm{m} .\end{array}$ & $\begin{array}{c}\text { Gravimetric } \\
\text { elevation } \\
\mathrm{m} .\end{array}$ \\
\hline $\mathrm{MI}_{\mathrm{I}}$ & 1957 & $\mathrm{I}, 45^{\mathrm{I}}$ & $\mathrm{I}, 3 \mathrm{IO}$ \\
\hline $\mathrm{M} 2$ & 1957 & 1,364 & 1,330 \\
\hline $\mathrm{S}_{\mathrm{I}}$ & $195^{8}$ & 1,355 & I, 335 \\
\hline $\mathrm{S}_{2}$ & 1958 & 1,410 & 1,360 \\
\hline $\mathrm{L}$ & 1959 & $\mathrm{I}, 47 \mathrm{I}$ & $\mathrm{I}, 480$ \\
\hline B & $196 \mathrm{I}$ & 1,362 & 1,360 \\
\hline $\mathrm{J}$ & 1963 & 1,523 & 1,520 \\
\hline
\end{tabular}

Seismic reflections were measured by M. F. Meier, C. R. Allen, W. B. Kamb and R. P. Sharp at a number of locations in 1957 (Fig. 6). Although some of the results are questionable, the bedrock elevations calculated from them are compared with model III in Table IV. Bedrock elevations at the seismic stations are based on surface elevations of $1960-6$ I and are corrected for the slope of the bedrock (as determined from the reflections) in order to give the elevation below the station. The measurements have a precision of about ro $\mathrm{m}$. and their correspondence with model III is remarkably good. Mean difference of the 8 elevations from good or excellent seismic reflections and the gravimetrically determined elevations is $\mathrm{I}$ o $\mathrm{m}$. and four-fifths of all of the comparisons result in differences of less than $20 \mathrm{~m}$. Because of the inexact nature of both the seismic values and the gravimetric results, it appears that no additional modifications need be made to model III. 


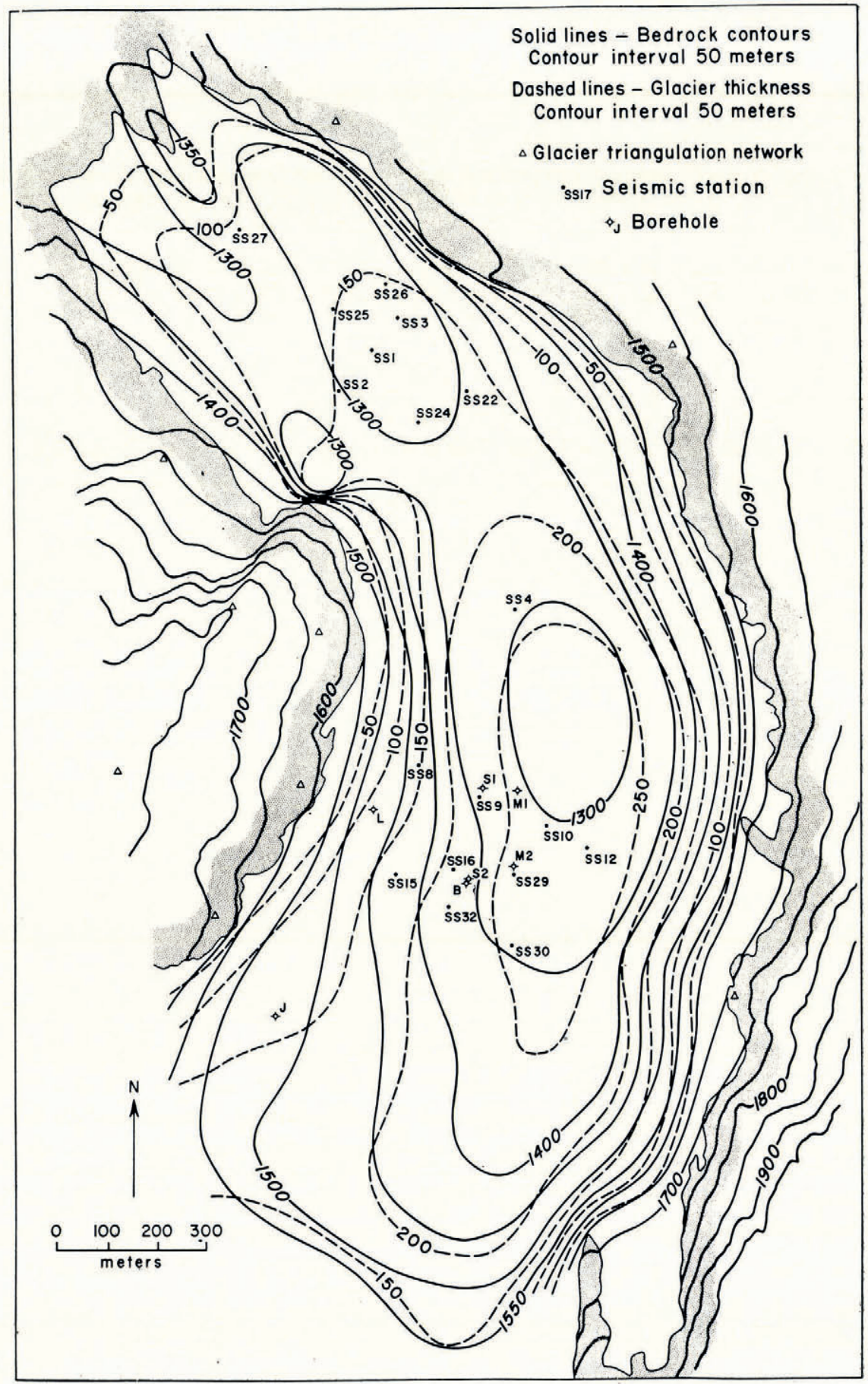

Fig. 6. Model III. Bedrock contours based on three-dimensional procedure and resulting thicknesses 
Table IV. Comparison of Gravimetrically Determined Elevations and Elevations Determined by Seismic Reflections

\begin{tabular}{|c|c|c|c|c|}
\hline $\begin{array}{l}\text { Seismic } \\
\text { station }\end{array}$ & $\begin{array}{c}\text { Elevation } \\
\text { of reflection } \\
\text { (corrected for slope) } \\
\mathrm{m} .\end{array}$ & $\begin{array}{l}\text { Gravimetric } \\
\text { elevation } \\
\mathrm{m} .\end{array}$ & $\begin{array}{c}\text { Difference } \\
\mathrm{m} .\end{array}$ & $\begin{array}{l}\text { Quality } \\
\text { of } \\
\text { reflection }\end{array}$ \\
\hline I & 1,260 & $\mathrm{I}, 280$ & -20 & fair-poor \\
\hline 2 & 1,265 & $\mathrm{I}, 300$ & -35 & poor \\
\hline 3 & 1,280 & 1,290 & -10 & fair \\
\hline 4 & 1,305 & 1,305 & o & excellent \\
\hline 8 & $1,3^{85}$ & $\mathrm{I}, 430$ & -55 & poor \\
\hline 9 & 1,328 & 1,345 & -17 & good \\
\hline 10 & 1,312 & 1,305 & +7 & good \\
\hline 12 & 1,318 & 1,310 & $\begin{array}{r}1 \\
+8\end{array}$ & poor \\
\hline I5 & 1,4 II & 1,430 & -19 & poor \\
\hline 16 & 1,357 & 1,375 & -18 & excellent \\
\hline 22 & 1,298 & 1,305 & -7 & poor \\
\hline 24 & 1,278 & 1,290 & $-\mathrm{I} 2$ & good-excellent \\
\hline 25 & $\mathrm{I}, 25^{8}$ & 1,290 & $-3^{2}$ & fair-poor \\
\hline 26 & $\mathrm{I}, 285$ & $\mathrm{I}, 290$ & -5 & fair \\
\hline 27 & 1,290 & 1,310 & -20 & poor \\
\hline 29 & 1,332 & 1,330 & +2 & good-excellent \\
\hline 30 & 1,367 & $\mathrm{I}, 35^{\circ}$ & +17 & good-excellent \\
\hline $3^{2}$ & 1,381 & $\mathrm{I}, 375$ & +6 & excellent \\
\hline
\end{tabular}

\section{Conclusion}

The measurement of gravity anomalies on valley glaciers can be a useful method for determining the subglacial bedrock configuration. Accuracy in every step of the procedure and a minimum of assumptions are necessary to produce meaningful results. Aspects of the problem which are most critical and demand the most attention are: observed gravity anomalies, station elevations, density contrast, terrain corrections, regional gravity field and three-dimensional interpretation. Resulting thicknesses can then be accurate to within $5^{-10}$ per cent of the actual thickness of the glacier.

The thickness of Blue Glacier has been determined by a series of successive approximations resulting in a three-dimensional model which fits the observed gravity anomalies within the range of observational and computational error. Correlation with topographic features on the margins of the glacier is high and comparison with bore holes and available seismic information does not indicate any significant errors in the resulting subglacial bedrock configuration.

\section{Acknowledgements}

Support for this project came from many sources. Ivo Lucchitta, Thomas Bjorkland, David Schleicher and Ronald Gebhardt assisted in surveying. Ronald Surdam and Katherine Horn helped in computations and the reduction of the data. Professor Hewitt Dix of the California Institute of Technology arranged the loan of a gravity meter. Mrs. Opal Kurtz drafted the illustrations. The Computing Facility of the University of California, Los Angeles, provided time on their IBM 7090 high-speed digital computer. The National Park Service aided the field aspects of the project in innumerable ways as did Mr. William R. Fairchild of the Angeles Flying Service, Port Angeles. Professor Clarence R. Allen provided the unpublished results of the previous seismic survey on lower Blue Glacier. Professor Ronald L. Shreve, through his many discussions, aided the task of interpretation immeasurably. Professor Robert P. Sharp assisted in the field and in the logistics. Professors Allen and Shreve, Dr. Thane H. McCulloh and Dr. Roland E. von Huene critically reviewed the manuscript. Support for the field work was provided in part by Professor Sharp (National Science Foundation grant Gi 7688) and by a grant-in-aid from the Institute of Geophysics, University of California, Los Angeles. The author wishes to thank all of the above for their generosity.

MS. received 13 November 1964 


\section{REFERENCES}

American Geographical Society. 1960. Nine glacier maps: northwestern North America. American Geographical Society. Special Publication No. 34.

Bull, C., and Hardy, J. R. 1956. The determination of the thickness of a glacier from measurements of the value of gravity. Fournal of Glaciology, Vol. 2, No. 20, p. 755-63.

Caputo, M. 1958. La profondità del ghiacciaio Baltoro ad Urdukass determinata con metodo gravimetrico, e per mezzo della sua velocità superficiale (metodo di Somigliana). Geofisica e Meteorologia, Vol. 6, No. 3-4, p. $33-36$.

Corbató, C. E. 1963. Bouguer gravity anomalies of the San Fernando Valley, California. University of California. Publications in Geological Sciences, Vol. 46, No. I, p. I-32.

Corbató, C. E. I 964 . Theoretical gravity anomalies of glaciers having parabolic cross-sections. Journal of Glaciology, Vol. 5, No. 38, p. 255-57.

Corbató, C. E. I 965 . A least-squares procedure for gravity interpretation. Geophysics, Vol. 30, No. 2, p. $228-33$.

Hammer, S. r 939. Terrain corrections for gravimeter stations. Geophysics, Vol. 4, No. 3, p. 184-94.

Kanasewich, E. R. 1963. Gravity measurements on the Athabaska Glacier, Alberta, Canada. Journal of Glaciology, Vol. 4, No. 35, p. 61 7-31.

Roy, A. 1962. Ambiguity in geophysical interpretation. Geophysics, Vol. 27, No. I, p. 90-99.

Russell, R. D., and others. 1960. Gravity measurements on the Salmon Glacier and adjoining snow field, British Columbia, Canada, by R. D. Russell, J. A. Jacobs and F. S. Grant. Bulletin of the Geological Society of America, Vol. 71, No. 8, p. 1223-29.

Seligman, G. I950. The specific gravity of ice. Journal of Glaciology, Vol. 1, No. 8, p. $44^{2}$.

Skeels, D. C. 1947. Ambiguity in gravity interpretation. Geophysics, Vol. 12 , No. I, p. 43-56.

Stuart, D. J. 1961. Gravity study of crustal structure in western Washington. U.S. Geological Survey. Professional Paper 424-C, p. $273-76$.

Talwani, M., and Ewing, M. 1960. Rapid computation of gravitational attraction of three-dimensional bodies of arbitrary shape. Geophysics, Vol. 25, No. I, p. 203-25.

Talwani, M., and others. I959. Rapid gravity computations for two-dimensional bodies with application to the Mendocino submarine fracture zone, by M. Talwani, J. L. Worzel and M. Landisman. Fournal of Geophysical Research, Vol. 64, No. I, p. 49-59.

Thiel, E., and others. 1957. The thickness of Lemon Creek Glacier, Alaska, as determined by gravity measurements, by E. Thiel, E. [R.] LaChapelle and J. [C.] Behrendt. Transactions. American Geophysical Union, Vol. 38, No. 5, p. $745-49$. 